\title{
El Municipio: entre el Poder Local y los Actores Políticos
}

\author{
María Concepción Martínez Omaña \\ Instituto Mora \\ Antonio Padilla Arroyo \\ Escuela de Humanidades \\ Universidad Autónoma del Estado de Morelos
}

Resumen: El artículo aborda las relaciones políticas entre el Estado y el municipio, a partir de consideraciones teóricas y metodológicas, apoyándose en autores especialistas en la materia, así como en consideraciones propias acerca de los cambios que ha tenido este tipo de relación.

Abstract: This paper introduces a study about local governments and the state; mostly based in a theorical and methodological perspective, supporting it's arguments with other specialists and the particular vision of the authors about the changes in these kind of relationship.

\section{Introducción}

Dara el examen de las relaciones políticas entre el Estado y el municipio es conveniente formular un enfoque interdisciplinario que recupere los métodos, teorías y categorías de las distintas disciplinas sociales, particularmente de la antropología, la ciencia política, la sociología y la historia, así como los "nuevos enfoques", los temas de estudio y las problemáticas originales que han investigado esas disciplinas, lo que significa recuperar a actores, instituciones y grupos que habían permanecido ignorados y olvidados debido no sólo a la naturaleza de las perspectivas prevalecientes en la creación de las teorías, sino por una actitud voluntaria, inconsciente o consciente, al considerar que poco podían decirnos estos olvidados sobre aspectos específicos de la realidad social.

El Estado, con mayúsculas, fue considerado durante mucho tiempo como el actor central de los procesos de articulación de la nación, del poder, de las relaciones entre dominantes y dominados, de los gobernantes y gobernados. De igual modo, tanto la legitimidad como las formas de gobernabilidad, los tipos de dominación y de gobierno han sido el eje desde la cual se articulaban las investigaciones y 
orientaban gran parte de las preocupaciones y de los temas del derecho, la sociología, la historia, la antropología y la ciencia política; esto puede tener diversas razones, entre ellas, una que consideramos fundamental: estas disciplinas surgieron casi al mismo tiempo que el Estado moderno, situación que las mantuvo muy vinculadas al estudio del territorio, la cultura, la identidad y la formación de los grupos sociales que daban sustento a prácticas y modos de relacionar la vida de los grupos humanos con las nacientes instituciones, los nuevos hábitos, las costumbres y las normas legales.

En todo caso la profunda reflexión, tanto interna como externa, a la cual ha sido sometida la ciencia social, en las últimas dos décadas por lo menos, es en gran medida reflejo de la propia crisis de la ciencia en general, de los postulados que la sustentaban: el progreso, la razón y la felicidad. La crítica interna se ha orientado a la creación de paradigmas y núcleos "duros" de conocimiento, con el propósito de establecer un lenguaje común y un acervo de conocimientos, conceptos básicos y generales, consensados por las comunidades de investigadores sociales, mientras que la crítica externa proviene de las ciencias naturales y de instituciones que están por fuera de las comunidades "científicas", pero que actualmente dictan las políticas, los temas de investigación y aún las propias formas de realizar el análisis social; esto ha obligado a establecer nuevas maneras de enfocar los trabajos en las ciencias sociales.

Estas nuevas líneas de investigación se interesan no sólo por las estructuras y las instituciones totales, los grandes actores o personajes que crean y reproducen unas y otras, así como por las identidades nacionales o de clase, sino también por los actores, las estructuras más menudas y poco perceptibles, igualmente creadoras de identidades locales y regionales. En este marco destaca el estudio de las nuevas relaciones entre Estado y municipio, entre cultura política nacional y cultura política regional, entre identidad global e identidad regional, entre federalismo y centralismo, riqueza y pobreza, autonomía y nación, entre ciudadano y comunidad, movimientos de clase y movimientos ecologistas o de derechos humanos. Ello necesariamente supone una nueva definición de relaciones entre estas supuestas o reales dicotomías, lo que requiere buscar matices en la teoría y en la forma de pensar nuestros hallazgos y conclusiones. En suma, la necesidad de indagar sobre problemas reales y ofrecer explicaciones bajo nuevas formas de pensamiento e interpretación. 


\section{Lo local: entre el municipio y el Estado}

Las ciencias sociales mostraron un particular interés por el estudio del municipio durante la década de los años ochenta cuando el Estado benefactor sufre un proceso de transición hacia un nuevo modelo de acumulación capitalista, entre cuyas expresiones estuvieron sentar las bases para la administración y gestión de una larga crisis económica y la formulación de nuevos estilos de gobernabilidad. A mediados de esta década se instrumentaron iniciativas gubernamentales, entre las que destacaron reformas constitucionales para la descentralización y la reforma municipal que respondieran a las circunstancias de una reforma política inaplazable por la presencia cada vez mayor de fuerzas políticas de oposición. Este estado de cosas influyó en las disciplinas sociales, obligándolas a desarrollar investigaciones cuyos objetos de estudio fueran el municipio, el poder local, las luchas políticas y la descentralización.

Desde la sociología se avanzó en el estudio del significado político del municipio en relación con las luchas y las reivindicaciones democráticas, las cuales explican en gran medida la instrumentación de una reforma municipal que pretendía el eventual fortalecimiento de la representación política de nuevos actores. En México, a partir de la reforma política de 1977 y de los procesos electorales locales de 1982 y 1983, el objeto de análisis se orientó a examinar el sentido y la importancia del municipio en la constitución de los actores políticos y la conformación de los sistemas de representación e identidad ciudadana. Entre los trabajos que inauguraron esta línea de trabajo están, sin duda, los encabezados por Carlos Martínez Assad, Adriana López Monjardín y Alberto Aziz Nassif, entre otros. Al mismo tiempo, se emprendieron estudios que colocaron el énfasis en los límites jurídicos y políticos de las reformas constitucionales en relación con la autonomía, poniendo en entredicho las intenciones reales o supuestas de democratización de la vida política, pues la consecuencia más visible de ellas fue que reforzaron la secular subordinación de los gobiernos municipales a la federación y los gobiernos estatales, tanto económica como financieramente. También indagaron acerca del significado de la institución respecto a la soberanía popular, a la par del 
esfuerzo por comprender el origen y el desarrollo de la diversidad de las luchas municipales, en particular de las disputas por las alcaldías mediante los procesos electorales. ${ }^{1}$

Otra línea de investigación fue el estudio de las políticas de descentralización, lo que propició el examen del universo municipal a partir de la identificación de tres tipos de unidades político-territoriales: federación, estado, municipio, así como el estudio de las políticas de descentralización y fortalecimiento municipal, la evaluación de los avances y limitaciones de estas políticas, sobre todo a partir de los cambios económicos, políticos y sociales impulsados por ellas, junto con la problematización de las competencias de cada una de esas unidades en el desarrollo y la gestión urbana, sobre todo con las reformas introducidas en estas materias en $1983 .^{2}$

Por otro lado, la geografía y la antropología del poder se orientaron a elaborar estudios sobre poder local, en particular sobre el impacto de las transformaciones económicas, tanto en el territorio como en la integración de los poderes locales, a merced del impulso a los polos de desarrollo promovidos y planificados desde el poder central. Estas líneas de investigación, en efecto, no han sido exclusivas de México, sino también compartidas por estudiosos de Europa y América Latina, en un marco de crisis económica, democratización política, fortalecimiento de poder local y participación ciudadana. En fin, el municipio se ha convertido en centro de interés de la sociología, la ciencia política y la antropología política (Padúa y Vaneph, 1988).

De igual manera, la importancia de los estudios se ha visto incrementada en razón de la generalización de los conflictos por el control y ejercicio del poder municipal, los cuales manifiestan espacios

1 Los textos que aquí se citan son las primeras obras en las que los autores dieron a conocer futuras líneas de investigación y pensamiento que desarrollarían durante varios años, unos con mayor regularidad que otros, aunque puede asegurarse que ninguno de ellos se ha separado del campo de investigación. De igual modo, hacen referencia a sus trabajos de manera emblemática.

2 Como ejemplo de investigaciones sobre la descentralización pueden citarse los trabajos de Jordi Borja, Alicia Ziccardi, Ma. Concepción Martínez, Alejandra Massolo, así como en la línea de federalismo y municipio en términos de sus determinaciones juríddicas a Luis Aguilar Villanueva y Roberto Ortega Lomelín, las cuales aparecen en la bibliografía. 
desde donde se están redefiniendo las relaciones entre el Estado y el municipio, las nuevas formas y niveles de articulación entre una y otra institución. Asimismo las luchas municipales revelan los diferentes actores sociales y políticos, quienes han mostrado las complejidades de las relaciones entre la federación, los estados, las regiones y las localidades.

Por ello la pertinencia, desde nuestro punto de vista, de analizar y estudiar lo local con el propósito no sólo de establecer las relaciones formales entre Estado y municipio, sino de situar desde un contexto más amplio aspectos que "lo formal" no deja apresar. Por ejemplo, detrás de un problema municipal, es decir, al interior de una jurisdicción y territorio limitados en términos administrativos, o de un conflicto entre federación, Estado y municipio por competencias legales, pueden encontrarse los motivos que trascienden los límites territoriales o los derechos y obligaciones garantizados por la vía jurídica de ciudadanos y comunidades. En este sentido, el municipio en su carácter jurídico y político formal puede obstaculizar la comprensión cabal de los conflictos. Es decir, lo que quiere puntualizarse es que el municipio no necesariamente es una unidad analítica que por sí misma ayude a comprender los cambios que se están presentando entre el Estado y los municipios en nuestro país. Aquí se sostiene la conveniencia de formular un primer nivel analítico: examinar la dimensión local, el cual permite visualizar la trama y los tejidos de los conflictos y las luchas municipales.

Para ello pensamos que una categoría central es la del poder, entendido "como un aspecto de la estructura y la organización social". Sin duda, es preciso analizar empíricamente las modalidades que adopta la generación, la distribución, las prácticas, las costumbres, las normas y los hábitos en el ejercicio del poder porque éste se aplica y ejecuta en contextos socioculturales históricamente determinados. Son precisamente estos ámbitos socioculturales a los que nos referimos cuando indicamos que lo local no corresponde necesaria y obligadamente a los municipios tal y como están delimitados. De este modo, estaremos en posibilidad de explorar a los actores políticos y sociales que intervienen en la formación y el ejercicio del poder, e involucrar el estudio de los sujetos que lo reconocen, es decir, que lo legitiman por varias fuentes: el control de los recursos económicos o sociales, la creación de un imaginario social que se asienta en valores, estilos y formas de vida, cuyos depositarios asumen las autoridades, 
acceso a servicios y obras públicas, etc. Las características de los movimientos sociales, sus motivos y las formas de organización y liderazgo. En resumen, las modalidades de la relación entre gobernantes y gobernados, en los niveles federal, estatal y municipal.

Evidentemente esta propuesta metodológica y teórica requiere ser desglosada. Primero, el origen y la fuente de legitimidad precisa de un orden que sea reconocido y aceptado por los actores sociales y políticos. Un primer problema que se presenta es: ¿cómo se regula este orden y cuáles son sus características? Según Guillermo De la Peña (1986), es necesario estudiar las reglas e ideales sobre las cuales los actores, colectivos o individuales, establecen el consenso. Esto conlleva a precisar distintos niveles de la vida social: las normas y los valores, la conciencia y el imaginario colectivo. Es decir, las formas y las prácticas que adopta la identidad y la cultura. Al mismo tiempo, se requiere estudiar las estructuras e instituciones que garantizan la reproducción del imaginario colectivo particularmente aquellas que concretizan el poder y la autoridad legítimamente constituida tanto en términos formales como reales. Y aquí es fundamental distinguir entre la representación política formal de las autoridades elegidas por los vías jurídicas que enuncian las constituciones estatal, federal y local, así como los usos y costumbres de los municipios.

De nuevo estamos ante el problema de dilucidar la normatividad jurídica escrita que crea el Estado moderno y las prácticas de representación política y social de muchos municipios del país. Otro tema central que requiere ser despejado es el relativo a la posible contradicción entre distintas formas de representación política, de sobreposición de la una sobre la otra, de las mutuas relaciones entre ambas, de las contradicciones que subyacen, así como la lucha por imponer la una sobre la otra, aunque en condiciones adversas para las representaciones no jurídicas. Nos referimos al estudio de la cultura política. Precisamente, una de las ausencias más notorias de los análisis sobre los nexos entre Estado y municipio es no destacar esta complejidad y no ha sido sino hasta el estallido de la insurgencia zapatista en 1994, cuando los estudiosos repararon en este problema sustancial para nuevas relaciones políticas entre Estado y municipios en México. La pregunta que cabe hacernos es la siguiente: ¿por qué esta aparente o real contradicción entre norma jurídica y prácticas y modos concretos de actuación política? De las distintas respuestas que podamos formular a esta pregunta dependerá la comprensión cabal a la 
enorme complejidad y los desafíos que implican las relaciones entre Estado, federalismo y municipios, así como dilucidar un aspecto fundamental para comprender la nueva dinámica de las relaciones entre Estado y municipio. Nos estamos refiriendo al problema de los movimientos sociales que se dan alrededor y dentro del espacio territorial y político del municipio. Evidentemente, gran parte de la respuesta debe buscarse en la conformación de los nexos entre Estado y municipio, es decir, en la historia de esas instituciones. La heterogeneidad social y territorial de nuestro país, la conformación de la nación, las luchas y resistencias de los distintos grupos sociales dan por resultado las características de las relaciones entre Estado y municipio, entre federalismo y centralismo. ${ }^{3}$

Retomemos nuestra pregunta. Una primera idea, de orden conceptual, que puede orientar las investigaciones tiene relación con el tipo de sociedad imaginaria sobre la cual se ha levantado un discurso jurídico que pretende regular un orden, un poder y una legitimidad que formalmente cubre las relaciones entre Estado y municipio. Formalmente se reconoce la existencia de una república federal, democrática y popular con tres niveles de gobierno: federal, estatal y municipal, con competencias claramente determinadas. La base de estos tres órdenes son los ciudadanos que se conectan por medio del voto popular y en cuya base de representación se encuentra el municipio. Así, se asume que la sociedad mexicana cuenta con un Estado y una sociedad moderna, soportada, reproducida y legitimada por individuos que reconocen el orden de manera racional y libre como componente de la sociedad, es decir, por hombres y mujeres que al ejercer sus derechos y obligaciones adquieren la ciudadanía. Esto es, de acuerdo con De la Peña (1986), una sociedad y un Estado que "exige, por un lado, la disolución del orden corporativo (pre-capitalista) y por otro la soberanía de un Estado que surge para garantizar la acción individual”.

He aquí una de las mayores paradojas de nuestra situación política actual: ni estamos ante la presencia de un orden social basado en los

3 Cabe advertir que hay por lo menos tres formas históricas de creación de los municipios: el de raíces coloniales, el nacido de instituciones republicanas y el de una combinación de ambos. El estudio histórico puede arrojar luz sobre las relaciones entre éstos. 
individuos ni tampoco ante un Estado que ha disuelto las corporaciones. Estamos entrampados en una larga transición entre una sociedad organizada en corporaciones e individuos y un Estado centralizado apoyándose en ese orden, y una porción de la sociedad que reconoce esa organización corporativa, pero que se enlaza al reclamo moderno mediante la demanda del reconocimiento de derechos comunales y municipalistas. Estas circunstancias explican el sentido de las luchas en torno al control municipal y más aún regional, así como la aparición de una ciudadanía que exige plena autonomía municipal frente a las pretensiones de la federación y los gobiernos estatales de abrir espacios mínimos de participación en la gestión municipal. Por todo esto, el análisis de los nexos entre Estado y municipio tiene que ir más allá de la estructura formal, no sólo jurídica, y pasar al examen particular e histórico de las prácticas y de los modos de articulación entre ambas esferas. Para decirlo en palabras de De la Peña (1986: 32-36):

La centralización del poder -ni siquiera al aparecer el Estado moderno- no necesariamente destruye las partes constitutivas de la sociedad-llámese segmentos, o corporaciones, o unidades culturales-. La dialéctica entre tales partes constitutivas y el Estado moderno es, a mi juicio, el tema prioritario para la antropología política contemporánea

De este modo uno de los problemas a atender por las ciencias sociales, en el estudio particular de los nexos entre Estado y municipio, es retomar el análisis de "lo local", es decir, destacar las formas específicas de ejercicio del poder con el fin de determinar el significado de las luchas municipales y la redefinición que el Estado está obligado a realizar para reorganizar el consenso y la legitimidad. Profundizar en este punto permitiría comprender los procesos de cómo éste articula su dominación en un marco de creciente impugnación de sus formas tradicionales de ejercerla, basadas en el cacicazgo y el clientelismo como modos nacionales, así como la creación y recuperación de prácticas democráticas que se constituyen en alternativas que reclaman respeto a la identidad e intereses poniendo en el centro del debate el orden político jurídico formal. De ahí la importancia del estudio de los movimientos sociales que "expresan el cuestionamiento a las formas tradicionales y por ello, justamente, se tornan incontrolables, excepto por la fuerza para el orden nacional de dominio y sus aliados locales" (Villa, 1986: 17). 


\section{El municipio: escenario de identidades, actores y movimientos sociales}

No hay duda acerca de la importancia que ha adquirido el estudio del municipio. Uno de los aspectos más notables de este interés ha sido el relativo a los conflictos poselectorales que se han presentado en las últimas dos décadas, especialmente en los años noventa. Algo que pudiera parecer sorprendente es la fuerza que han tomado la reivindicación y la insurgencia municipal. ¿Qué factores y circunstancias explican la presencia de un vasto y vigoroso movimiento municipalista que, por primera vez en la historia del país, alcanza niveles de participación insólitos no sólo por la variedad de sus manifestaciones sino porque cubre todo el territorio? ¿Qué ha pasado en la sociedad mexicana para que el eslabón más débil de los tres órdenes políticos formales haya logrado tal presencia? ¿Qué representa para la vida política del país la insurgencia municipal en la formación de una auténtica ciudadanía social e individual? ¿Quiénes son los promotores y cuáles sus motivaciones e intenciones para embarcarse en una transformación de tal magnitud? (Meza y Padilla, 1991).

Para dar una respuesta general acerca de lo que significan las luchas municipales, así como los espacios de representación social y política de los ciudadanos en los municipios que hasta hace poco tiempo comenzaron a revelarse tras un complicado proceso de formación, que abarcó distintos niveles de la realidad social, cultural, política y cotidiana. En nuestro país puede recurrirse al que sintetiza este complejo entramado de procesos de participación política; en efecto, en el municipio hay una confluencia de actores, movimientos e identidades sociales que buscan nuevos espacios de interlocución ya sea entre sí mismos o con otras instancias de poder federal o estatal, con el propósito de ver satisfechas sus necesidades y sus demandas, lo que ha dado como resultado una participación ciudadana, social e individual que busca influir en la toma de decisiones del gobierno local mediante la representación política municipal. Tal vez, uno de los rasgos más significativos de esta intervención en los espacios públicos, sobre todo local, que afecta profundamente las relaciones entre Estado y municipio, encarna en el nuevo federalismo; en la medida en que por medio del poder federal y estatal buscan canalizar las expresiones de las organizaciones sociales del más distinto símbolo político y 
diversidad social. En gran medida estas organizaciones revelan un conflicto en distintos niveles: primero, contra las formas tradicionales de dominio que encarnan en la representación política del municipio, y segundo, contra una forma específica de apropiación del municipio, con el objetivo de refuncionalizar su uso para destinarlo a un empleo social de las atribuciones que formalmente le son asignadas, lo cual conlleva un nuevo significado por parte de las organizaciones e individuos que se empeñan en conquistarlo.

Así, inicialmente se trata de una resistencia a las formas de ejercicio del poder tradicional, las cuales articulan la dominación del Estado federal, estatal y municipal, y después de una apropiación de la estructura formal para darle una dimensión distinta, obligando a reformular las formas de dominación y legitimidad de los otros niveles de gobierno para lograr gobernabilidad. Es cierto que esas organizaciones y los ciudadanos pretenden resolver un problema concreto o bien defender una identidad colectiva. Las demandas que suelen enarbolar pueden parecer menudas o insignificantes pero son precisamente éstas las que permiten comprender y explicar la dinámica que imprimen a los gobiernos locales. Sin embargo, adquieren su peso real cuando se descubre que atrás de ellas hay una intrincada red de relaciones sociales que articulan nuevas o viejas prácticas, valores y creencias, así como modos de ejercer el poder local de manera informal, pero que son más reales que las normas legales y políticas formales.

Además, el ejercicio del dominio federal, específicamente presidencial, creó una cultura política que dejaba fuera los canales jurídicos formales de representación política y, en cambio, se expresaba en un imaginario que tenía por centro el Poder Ejecutivo federal o, en su caso, el estatal. El espacio local era dejado a las fuerzas caciquiles o clientelistas que bloqueaban las iniciativas sociales y se empleaban para fines estrictamente electorales. Acaso el ejemplo más extremo de esta forma de ejercicio de poder fue el PRONASOL durante la administración salinista.

Esta situación explica en gran medida la magnitud de los cambios tan profundos que han impuesto los movimientos sociales a los vínculos entre municipio y Estado. Por eso no ha sido fácil tanto para las organizaciones y los movimientos sociales como para los ciudadanos, transitar de la movilización social y política por demandas 
concretas a plantearse seriamente la alternativa de ejercer el poder municipal. Éste es uno de los elementos metodológicos más importantes que deben formularse en las investigaciones sobre la problemática municipal. Uno de los efectos más significativos de este proceso ha sido el aumento de la competencia electoral y la posibilidad real de alternancia en los partidos. El municipio ha dejado de ser, de acuerdo con Alberto Aziz Nassif, "un simple eslabón del aparato priísta, sus formas de gobierno estaban supeditadas al gobernador en turno y las posibilidades de participación social estaban enmarcadas en un patrón doble de obediencia regulada y de disciplina e interés partidiarios" (Aziz, 1995: 207).

Así, estamos ante el problema del enlace entre representación y participación. Para Mauricio Merino, esta relación supone "una circunstancia específica y a un conjunto de voluntades humanas, los dos ingredientes indispensables para que esa palabra adquiera un sentido concreto, más allá de los valores subjetivos que suelen acompañarla" (Merino, 1995: 19). Por su parte, Gerardo L. Munck (1995) ayuda a comprender la lógica interna y la externa que subyacen en estos dos elementos que apunta Merino, las voluntades humanas y la combinación de circunstancias específicas. Para Munck hay tres elementos centrales en la formación de las voluntades humanas, en su génesis como actores y movimientos sociales, en el paso del reino de la necesidad al reino de la libertad. Pero además contribuye a clarificar algunos aspectos del tránsito y de los momentos en que actores y movimientos comprenden la necesidad no sólo de resistir sino de apropiarse de instituciones políticas que habían aparecido distantes y hasta contradictorios a sus propias expectativas de movilización y lucha, es decir, Munck (1995: 17) destaca la importancia de "teorizar las conexiones entre los movimientos sociales y las instituciones políticas nacionales".

Munck destaca varios niveles que el estudioso debe tomar en consideración para inquirir sobre la dinámica de los movimientos sociales, definidos como "un tipo de acción colectiva orientada hacia el cambio por una masa descentralizada encabezada, de una manera no jerárquica, por un actor social": la formación de actores, la coordinación social y la estrategia política. Con base en las aportaciones de los estudios norteamericanos y europeos, en particular de los franceses, puntualiza el momento y los móviles en que surgen los actores, el cual se produce cuando un grupo de personas reflexionan en 
torno a su experiencia individual y social, cuyo interés está en cuestionar el orden existente, por lo que se plantean la necesidad de una identidad colectiva. Según sugiere el autor, este proceso de "toma de conciencia" se da en un marco de crisis estructural y por ende, cuando se reflexiona bajo la idea de conflicto. Esto supone, a su vez, un cuestionamiento de prácticas, ideas, creencias, hábitos y valores que han perdido legitimidad y autoridad para cohesionar e imponer el orden y las normas que lo regulan (Munck, 1995: 24-25).

El segundo nivel se orienta a determinar cuáles son los procesos de gestación de los movimientos sociales, es decir, bajo qué circunstancias se articulan los actores sociales con la "masa descentralizada", generalizan la identidad colectiva y amplían las redes sociales que cohesionan al movimiento. Al parecer, existe una identificación tanto subjetiva como objetiva que puede explicarse por marcos culturales que rodean a los miembros de la nueva "comunidad imaginada". Esto obviamente debe reconocer el tipo y la naturaleza de los liderazgos y de la masa. Por ejemplo, entre un movimiento ecologista o étnico, urbano o rural, de colonos o pequeños empresarios, etcétera. Es decir, redes sociales y marcos culturales son bastante heterogéneos. En todo caso, el proceso de articulación depende de la habilidad, conocimiento, comprensión y apropiación de la cultura de la masa, del manejo de símbolos, valores, costumbres y prácticas con el propósito de crear consensos, de la lealtad y confianza que se deposite en ello para brincar hacia la ampliación de relaciones culturales, políticas, sociales, de otras comunidades o de otras instancias más generales.

De ahí el tercer nivel analítico, aunque también un problema de naturaleza práctica concreta y cotidiana, que nos acerca más a nuestra preocupación por explicar las relaciones entre Estado y municipio, de manera especial, cómo los municipios pueden encarnar, y en la última década están encarnando sin querer negar la variedad y amplitud de sus manifestaciones, intereses y expectativas, la expresión de los movimientos sociales como ejercicio del poder local. Para Munck, este problema reside en la capacidad de los actores sociales o de los liderazgos para mantener la identidad y la autonomía del movimiento respecto a otras instituciones y, sobre todo, con las políticas, en nuestro caso los municipios o los partidos políticos. En resumen, en "cómo tienen que manejar los fundadores las relaciones con las instituciones nacionales con las que entra en contacto dada la orientación hacia el 
cambio de los movimientos sociales" (Munck, 1995: 28). Precisamente éste fue y es uno de los desafíos más importantes de los nacientes actores y movimientos sociales en su lucha por conquistar los municipios desde la década de los ochenta. ¿Por qué esta aparente paradoja y qué significan estos desafíos? Las respuestas son múltiples y variadas, pero en lo que no hay duda es que estas situaciones se explican porque la mayoría de la literatu- ra ha encontrado en los movimientos sociales formas y prácticas de organización de una emergente sociedad civil y signos de fortalecimiento de la ciudadanía. De este modo se explican los enormes esfuerzos que han hecho los actores sociales para persuadir a la masa descentralizada de la importancia y conveniencia de entrar en la arena política local, regional y nacional, debido a las dudas y la actitud recelosa de la masa frente a cualquier interlocución oficial o institucional, es decir, hacer viable una estrategia política de cambio social, lo que Munck define, con gran acierto, "estructura de la oportunidad política", sin dotarla del oportunismo, la ambigüedad de conductas y finalmente de cooptación, que no ha sido poco común entre los liderazgos actuales y pasados, que en gran medida se comprenden por las relaciones al interior de los movimientos sociales.

La articulación de los tres niveles analíticos permite entonces enriquecer nuestro marco analítico para comprender la enorme riqueza y complejidad de las actuales y futuras relaciones entre Estado y municipios, entre éste y los movimientos sociales, también entre Estado y sociedad civil y entre democracia y federalismo. De acuerdo con Munck, quien coincide con el sociólogo Anthony Giddens, esta perspectiva contribuye a entender y explicar que:

El Estado nacional es el 'recipiente' de poder más importante en la época moderna, (por lo que) los movimientos sociales están obligados a considerar las implicaciones de este poder estatal; necesitan un momento político. Por lo tanto, no sólo contribuyen a la democracia por medio de sus acciones 'dentro de la sociedad civil, a través de la democratización de relaciones en la sociedad civil, sino que existe una conexión entre los movimientos sociales y la democracia como una forma explícitamente política... Esta conexión es muy importante, desde el punto de vista de la teoría democrática, pues demuestra que no es suficiente entender el funcionamiento de la democracia a través del estudio exclusivo de las instituciones políticas. Aporta una invitación a repensar las contribuciones a la teoría democrática con base en el estudio de las élites y las instituciones políticas, como los partidos, las elecciones y las estructuras constitucionales, a la luz de la teoría de los movimientos sociales (Munck, 1995: $37)$. 
Entonces una pregunta pertinente es: ¿cuáles son las condiciones propicias para el nacimiento y desarrollo de los movimientos sociales? De acuerdo con Elizabeth Jelin algunas de éstas son:

a) La conciencia de la miseria $y$, por tanto, eliminar sus peores formas.

b) Enfrentar y dominar el autoritarismo.

c) El esfuerzo por establecer instituciones democráticas, es decir, crear sujetos de derecho en un marco en que éste se niega junto con los derechos fundamentales. En estos últimos años los organismos no gubernamentales han situado preferentemente su campo de acción en estos tres niveles, además de la defensa de los derechos humanos. Por eso, como uno de los principios vitales de los movimientos sociales, el esfuerzo por restablecer un cuerpo social que ha estado sometido al aniquilamiento moral, social y cultural y crear los medios para la creación de una dimensión social que rompa con el aislamiento, fortalezca la identidad, la comunidad y la humanidad.

No obstante su camino no ha sido fácil. Los movimientos sociales, expresión y revelación de grupos subordinados, enfrentan relaciones de poder asimétricas, lo que los ha obligado a desarrollar formas ocultas de acción para evitar su represión y control, defender su espacio social y crear un discurso disidente. Entre los resultados de esta situación está la presencia de una nueva ciudadanía, social e individual, que establece multiplicidad de dimensiones y nexos entre sistemas colectivos de reconocimiento social, de identidades colectivas con contenidos culturales y simbólicos que unen viejas tradiciones con nuevas prácticas de cohesión interna, así como liderazgos no partidiarios (Jelin, 1994: 93-97).

Precisamente una de las aportaciones más valiosas del estudio de los movimientos sociales ha sido introducir el papel de los actores como parte central de las estructuras, sistemas e instituciones y "llenar" los escenarios vacíos entre estructura y movimiento. De ahí que podamos definir los movimientos sociales como comportamientos colectivos en conflicto social que tienden a la ruptura de los límites del sistema, impuestos en tres niveles: modo de producción, organización social y sistema político. La profundidad y el sentido del movimiento estaría determinado por "La reacción del sistema afectado (que) suele 
ser un indicador importante para determinar el significado de la acción" (Giménez, 1994: 3-5).

Aquí conviene retomar el concepto de identidad social y colectiva, entendida como portadora de "emblemas de contraste", que marcan fronteras entre los grupos sociales y permite analizar el proceso de internalización selectiva de la cultura institucionalizada, es decir, los modos de apropiación y resistencia con que los grupos humanos recrean y reproducen prácticas, valores, creencias, etc., y de los intercambios culturales entre grupos dominantes y dominados. El examen de la identidad social requiere de distintos planos de reflexión y análisis para que su incorporación al estudio de los movimientos sociales, de los municipales y de la complejidad de las relaciones entre Estado y municipio tengan grado de comprensión. Para ello es útil y conveniente retomar las distinciones que propone Gilberto Giménez (1994) para el estudio de la identidad: las identidades étnicas, las cuales se basan "en la autopercepción subjetiva que tienen de sí mismos los actores llamados 'grupos étnicos"'. Éstos se caracterizan por su situación de minoría respecto a grupos y sociedades más amplias, así como por sus formas de vida y cultura "tradicionales" y no emergentes de solidaridad social con fuerte apego a su territorio; las identidades regionales, que subrayan la idea de una zona sociocultural, la cual "no se reduce a su dimensión ecológica, demográfica, económica o política, sino que también aparece revestida de un exhuberante ropaje simbólico que ha ido confeccionando en el curso del tiempo". En ese sentido es una "comunidad imaginada e imaginaria" que se afirma en un territorio y propicia intercambios sociales de base. Para Giménez (1994: 268-271) "la región vendría a ser un nivel intermedio de integración sociocultural entre el nivel nacional y el nivel local de las 'matrias'. En ella se apela a símbolos de pertenencia territorial y cultural: la música, el cancionero, la danza, la literatura y un panteón regional"

Creemos que es en la dimensión local y regional donde los actores y los movimientos sociales se han expresado con mayor claridad en términos de sus motivaciones y sus identidades. Es desde estos niveles como puede entenderse mejor el sentido de las relaciones entre municipio y Estado. Para decirlo en otras palabras, se trata de estudiar las relaciones entre actores y espacios regionales a fin de desentrañar los mecanismos de instauración del poder local, regional y municipal. Así, entre los objetivos de las investigaciones que propusieran su 
estudio estaría: "Distinguir los elementos que integran esta estructura, las transformaciones que sufre, su funcionamiento general y las formas en que los actores del movimiento se relacionan e incluso se insertan en ella", lo cual permitiría tener una imagen más nítida de la realidad y de la complejidad que encierran los vínculos entre Estado y municipio, entre éste y el gobierno estatal, entre actores y movimientos (Tamayo y Cárdenas, 1994: 28).

\section{Consideraciones finales. El federalismo, ¿una alternativa hacia el futuro?}

En este marco, ¿qué es lo que ha cambiado en los lazos entre Estado y municipios? ¿qué sentido tiene hablar de nuevo federalismo? En primer lugar, ha variado la percepción sobre el centro y la región, es decir, entre el poder federal y el local. Con ello queremos decir que las prácticas, los modos, los hábitos y los valores sobre el "hacer política" o la cultura política han cambiado notablemente. Así, el respeto al poder local, fincado en estructuras de control y autoridad, así como las jerarquías, la rotación del cuerpo político y los administradores del poder local en un territorio determinado, que garantizaban la obediencia al poder estatal y federal y mantenían la paz y la estabilidad del poder federal y el PRI, han sufrido una profunda transformación. La presencia de nuevos liderazgos sociales y la expresión de los nuevos grupos sociales, han roto con el monopolio de la representación y de la participación política.

Por eso insistimos en que estamos ante la urgencia de un nuevo pacto entre el centro y las regiones que sólo puede fructificar si está sostenido sobre las bases mismas de las organizaciones sociales que encarnan las expectativas y las aspiraciones de nuevos o viejos actores políticos y sociales. Sólo esto garantizaría que la estabilidad y la gobernabilidad de las representaciones democráticas no dependieran de factores externos al desempeño adecuado del mismo municipio, tales como los gobiernos estatales, los congresos y la federación . Los ejemplos de cómo estos factores interfieren en la búsqueda del reconocimiento pleno a las gestiones municipales y de gobierno local pueden ser varios: conflictos políticos por competencias estatales o federales, como el caso de los municipios de Guadalajara o Tijuana, o bien, los más comunes provenientes de decisiones en el ámbito financiero que se cruzan con la forma de distribución de los recursos y los intentos de fortalecimiento municipal (Aziz, 1995: 212-213). 
Estos conflictos en realidad significan:

...un gran desconocimiento por parte de la república de lo que es su célula fundamental, pero que no permite olvidar que lo que impera, en todos los casos, es una subordinación en la que se entretejen la política, el poder y las inercias de una administración pública inveteradamente centralista, incapaz de registrar lo local o lo regional como entidades con capacidad de acción autónoma a la vez que integradora (Cordera, 1995: 225)

Una vez ubicados los principales dilemas y desafíos que representan los nuevos enlaces o el nuevo pacto entre Estado y municipios, ¿dónde situar el nuevo federalismo, tanto en la estrategia del Estado mexicano, en particular de la actual administración gubernamental, como de los propios movimientos sociales agrupados alrededor y en el poder municipal? Desde la visión gubernamental, la piedra de toque del federalismo, en una estrategia de largo plazo y de acuerdo con los ritmos de los poderes tradicionales, incluido el federal, intentarían imponer para recomponer su dominación y su legitimidad sin afectar demasiado su propia presencia y su ejercicio de poder, estaría la desaparición paulatina de los programas federales y la transferencia de sus fondos a los municipios hasta garantizar cierta estabilidad política que los favoreciera, es decir, que no pusiera en tela de juicio la gobernabilidad de los otros órdenes. Por otro lado, el municipio "democrático" y las fuerzas políticas que lo promueven no asegurarían una plena vigencia del municipio como poder local y expresión de la ciudadanía simplemente con una gestión eficiente y honesta, sino con la implantación y promoción de prácticas democráticas cotidianas.

No es suficiente descentralizar recursos; es indispensable un ejercicio democrático del poder que recoja la heterogeneidad de modos y costumbres, así como de valores y creencias de ejercicio de poder social o individual. En una palabra, llevar estas formas de cultura política al espacio público, desprivatizarlas y desde abajo impulsarlas hacia los otros niveles de gobierno. Estamos de acuerdo con el planteamiento general de Cordera Campos sobre la enorme tarea de construir un poder local sobre nuevas bases y, por tanto, reconstruir las relaciones entre Estado y municipios bajo un aspecto de la reforma del Estado, el nuevo federalismo: "Lo que está por delante es la transformación de este reclamo, que es de ética y de eficiencia a la vez, en nuevas formas culturales positivas, que orienten no sólo una desprivatización, sino una construcción del espacio público que sea 
congruente con las nuevas formas colectivas de pensar del gobierno, la ciudadanía y la contienda política que han hecho surgir las movilizaciones democráticas" (Cordera, 1995: 229-230).

¿Cuáles son los rasgos de estas nuevas formas de representación y participación ciudadana que encarnan en los municipios? Desde nuestro punto de vista las características de estos gobiernos locales son: la democracia que implica el reconocimiento de la pluralidad, la transparencia en las decisiones, la vigencia de la legalidad y la apertura de las autoridades, producto de los cambios en la estructura de la población, los avances de la modernización, la escolaridad y la urbanización. En este sentido, volvemos a insistir, se expresa con claridad una nueva cultura política que, al mismo tiempo, manifiesta una redefinición del espacio privado al público, transitando del temor y la crítica privada hacia una mayor conciencia de organización y participación colectiva e individual, en un ejercicio de los derechos elementales de opinar, exigir y protestar.

Sin embargo, debemos subrayar que gran parte de los enfoques sobre las nuevas conexiones entre el Estado y el municipio han insistido en el enfoque de la innovación y la gestión municipal desde la perspectiva de la administración pública o del derecho constitucional, olvidándose de la importancia de analizarlas desde distintos enfoques disciplinarios: la cultura, la antropología, la sociología y la política. Aquellas destacan en sus análisis de los aspectos del pacto federal que tienen relación con la coordinación fiscal y la promoción del desarrollo. Así centran su interés en los avances del federalismo, examinando las políticas de descentralización, distribución de competencias entre la federación y los estados, el sistema de coordinación fiscal, los convenios de desarrollo, la canalización de recursos, etcétera (Ocaña, 1996: 44-45).

Sin duda, ello ha permitido avances importantes en la comprensión de la dinámica entre Estado y municipio, pero ha sido insuficiente al abstraer o ignorar las estructuras reales de poder local y regional, la presencia de nuevos actores y movimientos sociales, el sentido estratégico que han adquirido los ayuntamientos para éstos y el tránsito de una cultura política autoritaria y clientelista a una de mayor democracia y participación ciudadana. Desde este punto de vista, ¿Cuáles son y pueden ser las contribuciones de esta propuesta en relación con el "nuevo federalismo"? Creemos que serían varias. En 
primer lugar, ubicar en un marco adecuado la importancia y las transformaciones que han sufrido los actores y los movimientos sociales sobre el sentido de la lucha municipal, regional o estatal.

De este modo, se pasa de una actitud antiestatista y de rechazo a instituciones formales ligadas directamente al aparato de Estado, en particular, al Ejecutivo federal, a un comportamiento colectivo que tiende a apropiarse de éstos desde la base, reasignándoles funciones individuales y sociales, convirtiendo al municipio en un nuevo tipo de institución al dotarle de nuevas funciones. En este sentido, los movimientos sociales que han establecido alianzas con los partidos de oposición han empujado, en el ámbito regional, al federalismo. Así, los propios partidos políticos se han visto obligados a una mécanica de descentralización buscando asentarse en los espacios locales y aceptando nuevas prácticas y modos de cultura política. En segundo lugar, porque posibilita el examen de los actores políticos y sociales que intervienen en la redefinición federalista, es decir, analizar los mecanismos de reclutamiento político con base en identidades locales y regionales, del surgimiento y la formación de actores sociales y de la definición del tipo de estrategia política que diseñan. Asimismo permite dilucidar la injerencia e intervención de los gobiernos estatales para favorecer u obstaculizar el nacimiento de nuevos líderes sociales $\mathrm{y}$, sobre todo cuando éstos se convierten en gobierno local institucional, en el reparto de los apoyos económicos a los municipios, así como las redes sociales y políticas entre los municipios, los congresos estatales y el Congreso de la Unión (Ocaña, 1996: 48-54).

\section{Bibliografía}

Aguilar Villanueva, Luis (1996), "El federalismo mexicano: funcionamiento y tareas pendientes", en Revista Mexicana de Sociología, año LVIII, núm. 3, julio-septiembre, México: IIS/UNAM.

Aziz Nassif, Alberto (1995), "Municipio y transición política: una pareja en formación", en En busca de la democracia municipal. La participación ciudadana en el gobierno local mexicano, México: El Colegio de México.

(1987), "Chihuahua y los límites de la democracia electoral", en Revista Mexicana de Sociología, año XLIX, núm. 4, octubre-diciembre, México: IIS / UNAM.

Borja, Jordi (1984), "La descentralización una cuestión de método", en Revista Mexicana de Sociología, año XLVI, núm. 4,octubre-diciembre, México: Instituto de Investigaciones Sociales.

Cordera Campos, Rolando (1995), "Los municipios y las discontinuidades nacionales", en En busca de la democracia municipal. La participación ciudadana en el gobierno local mexicano, México: El Colegio de México. 


\section{María Concepción MartínezOmaña/Antonio Padilla Arroyo}

De la Peña, Guillermo (1986), "La antropología cultural y estudio del poder", en Poder y dominación. Perspectivas antropológicas, septiembre, Caracas: URSHLAC-EI Colegio de México.

Giménez, Gilberto (1994), "Los movimientos sociales. Problemas teórico-metodológicos”, en Revista Mexicana de Sociología, año LVI, núm. 2,abril-junio, México: IIS / UNAM.

(1994), "Modernización, cultura e identidades tradicionales en México", en Revista Mexicana de Sociología, año LVI, núm. 4, octubre-diciembre, México: IIS/UNAM.

Jelin, Elizabeth (1994), “¿Ciudadanía emergente o exclusión? Movimientos sociales y ONG’S en los años noventa”, en Revista Mexicana de Sociología, año LVI, núm. 4, octubre-diciembre, México: UNAM, Instituto de Investigaciones Sociales.

López Monjardín, Adriana (1987), Los ayuntamientos : una utopía viable, México: Siglo XXI Editores.

Martínez Assad, Carlos (coord.) (1985), Municipios en conflicto, México: IIS / UNAM.

Martínez Omaña, Ma. Concepción (1994), Aguascalientes : un ensayo de descentralización (1982-1988), México:Instituto Cultural de Aguascalientes-Instituto Mora.

Massolo, Alejandra (1991), Descentralización y reforma municipal : ¿fracaso anunciado y sorpresas inesperadas?, (mimeo).

Merino, Mauricio (coord.) (1995), En busca de la democracia municipal. La participación ciudadana en el gobierno local mexicano, México: El Colegio de México.

Meza, Gilberto y Antonio Padilla (1991), Los nuevos electores. Actores sociales e insurgencia municipal en el México de los 80, México: El Nacional.

Munck, Gerardo L. (1995), "Algunos problemas conceptuales en el estudio de los movimientos sociales", en Revista Méxicana de Sociología, año LVII, núm. 3, julio-septiembre, México: IIS / UNAM.

Ocaña, Lucila (1996), “La recomposición del pacto federal”, en Revista Mexicana de Sociología, año LVIII, núm. 1, enero-marzo, México: IIS / UNAM.

Ortega Lomelín, Roberto (1994), Federalismo y municipio, México: FCE.

Padúa, J., y A. Vaneph (coords.) (1988), Poder local, poder regional, México: El Colegio de México.

Tamayo, Jorge y Elisa Cárdenas Ayala (1994), "El movimiento campesino y la dimensión regional", en Revista Mexicana de Sociología, año LVI, núm. 2, abril-junio, México: IIS / UNAM.

Villa Aguilera, Manuel (1986), "La antropología política y los niveles nacional, regional y local del poder", en Poder y dominación. Perspectivas antropológicas, septiembre, Caracas: URSHLAC-El Colegio de México.

Ziccardi, Alicia (1993), "Descentralización y espacio local”, en Secuencia. Revista de historia y ciencias sociales nueva época, núm.25, enero-abril, México: Instituto Mora. 